\title{
Chapter 15 \\ Rethinking Approaches for the Study of Urban Movement at Ostia
}

\author{
Katherine A. Crawford
}

\begin{abstract}
Despite a range of existing approaches for examining movement within ancient cities, the study of movement intent has received limited attention. This paper begins to address this gap by considering how pedestrian movement can be studied at Ostia, Rome's ancient port, by transitioning focus to what structured movement routes, namely the built environment and social activity. Using the UNA (Urban Network Analysis) Toolbox developed for ArcGIS, betweeness centrality is calculated in relation to different types of buildings. The results, when associated with Ostia's streets, provide a visualization of potential areas of movement specific to certain social activities that occurred within the urban landscape. This provides a novel methodological approach for assessing different forms of directed movement within ancient urban landscapes.
\end{abstract}

Keywords Urban Network Analysis · GIS · Archaeology · Ostia

\subsection{Introduction}

The study of movement within ancient Roman cities has seen a growing corpus of scholarship in recent years (Laurence 2008; Laurence and Newsome 2011; Östenberg et al. 2015; Poehler 2017). While the majority of research has followed either literary accounts of ancient movement (Favro 1996; Laurence 2011) or proxy evidence that is indicative of movement (Ellis 2004; Hartnett 2008, 2017; Poehler 2017), an increasing number of studies are beginning to apply computational approaches as a way to study pedestrian movement that is otherwise invisible within the archaeological record (Stöger 2011; Van Nes 2014).

Network science methodologies constitute one of the most frequently used methods for examining pedestrian movement, providing a quantitative approach for studying urban movement patterns that have developed out of modern urban planning techniques (Barthelemy 2011; Porta et al. 2006; Sarkar 2013). In particular, the

K. A. Crawford $(\bowtie)$

University of Southampton, Southampton, UK

e-mail: k.a.crawford@ soton.ac.uk 
application of space syntax theories and methods, developed by Hillier and Hanson (Hillier and Hanson 1984) for spatial analysis, has been predominantly applied to questioning how ancient street systems structured movement (Kaiser 2011; Stöger 2011). However, such methods do not address questions concerning different types of pedestrian movement or movement with varying intents.

Roman pedestrian research is largely limited to the analysis of random movement patterns that are structured by a city's street network. Studies of movement intent, movement with intended goals, that use computational approaches have received very little attention (Branting 2004; Poehler 2016; Thaler 2005). The majority of pedestrian movement, arguably, would have occurred with pedestrians having intended destinations or varying levels of knowledge of the urban landscape they traversed. And while the topic has received some attention in the context of Roman cities (Macaulay-Lewis 2011), the lack of engagement is largely due to the minimal trace that is left within the archaeological record and the limited written commentary about specific forms of movement. Thereby, any attempt to study pedestrian intent within a specific city is increasingly complicated.

This paper addresses this limitation by introducing a new computational approach for the study of directed urban movement that focuses upon how the built environment, indicative of social activity, may have played a role in structuring movement routes throughout a city. Using Ostia, Rome's ancient port, as a case study, this paper proposes a new way to look at how pedestrian movement can be studied within the late second century CE city. The size of the city and the extent to which it has been excavated make Ostia an ideal case study for applying an integrated computational approach that combines archaeological data, GIS, and urban network analysis (Sevtsuk et al. 2016), enabling the study of possible urban movement patterns.

\subsection{Methods}

\subsubsection{Modelling Movement Intent}

Recognizing the difficulties of studying urban movement, a new method needs to be developed that moves beyond studying how a city's streets promoted generic movement patterns. One way to approach this is by questioning how a city's built environment and corresponding social activity played a role in structuring different types of urban movement. Scholars have long recognized the relationship that existed between a city's built form and social activity (Lawrence and Low 1990; Rapoport 1982). Various urban theorists have focused attention upon how people understand and inhabit cities as well as how a city should be structured to promote different forms of social activity (Jacobs 1961; Kostof 1985; Lynch 1960). In terms of Roman studies, these theories have been adapted by scholars such as MacDonald 
(1986) to gain a better understanding about how people both interacted with and experienced a city.

Despite the acknowledged correlation between the built environment and social activity, questions of different types of ancient pedestrian movement have yet to be addressed with appropriate methodological rigour. The predominant methodologies for studying Roman pedestrian movement adopt either phenomenological approaches informed by random walks through the city (Favro 1996; Yegül 1994) or apply computational approaches like space syntax that consider movement in terms of a city's street network design (Stöger 2011). In both instances, the pedestrian movement under consideration is random and does not account for other urban dynamics that influenced pedestrian routes. By transitioning focus back towards how a city influences movement patterns, beyond solely its visibility or geometric design, a more nuanced approach can be developed for looking at ancient urban movement.

\subsubsection{Ostia's Urban Landscape}

In order to question how Ostia's built environment shaped different pedestrian movement patterns, a detailed plan of the second century CE built environment and street network is required. The excavated city represents a palimpsest of periods ranging from the end of the fourth century BCE into the sixth century CE (Pavolini 2006). The present study focuses upon the end of the second century CE because it represents one of the most well-defined periods for Ostia's urban landscape (DeLaine 2005). The extensive number of studies into buildings dating to the second century CE means that the built environment and corresponding streets are relatively well identified (Calza 1953; DeLaine 2002; Mar 2008; Meiggs 1973; Pavolini 2016). The extent to which the city has been excavated and knowledge of its street network provide an excellent opportunity to study pedestrian movement dynamics within the city.

Following a general conception of Roman urban space, buildings are classified within five broadly defined categories of space: commercial, production, residential, public, and religious (Fig. 15.1). These classifications do not negate the complexity of urban space, instead, they serve as an exploratory method to assess how different buildings, associated with specific types of social activity, shaped movement patterns within Ostia's urban landscape. All excavated buildings that compose the late second century CE city were classified into one of these five categories following their general architectural function (Flohr 2013; Heinzelmann 2005; Meiggs 1973; Packer 1971; Russell 2016). There is a certain degree of speculation within these classifications. First, due to how the site was excavated the purpose of many of the buildings has to be inferred through various comparative studies at Ostia and other Roman cities. Second, the majority of structures found at Ostia 


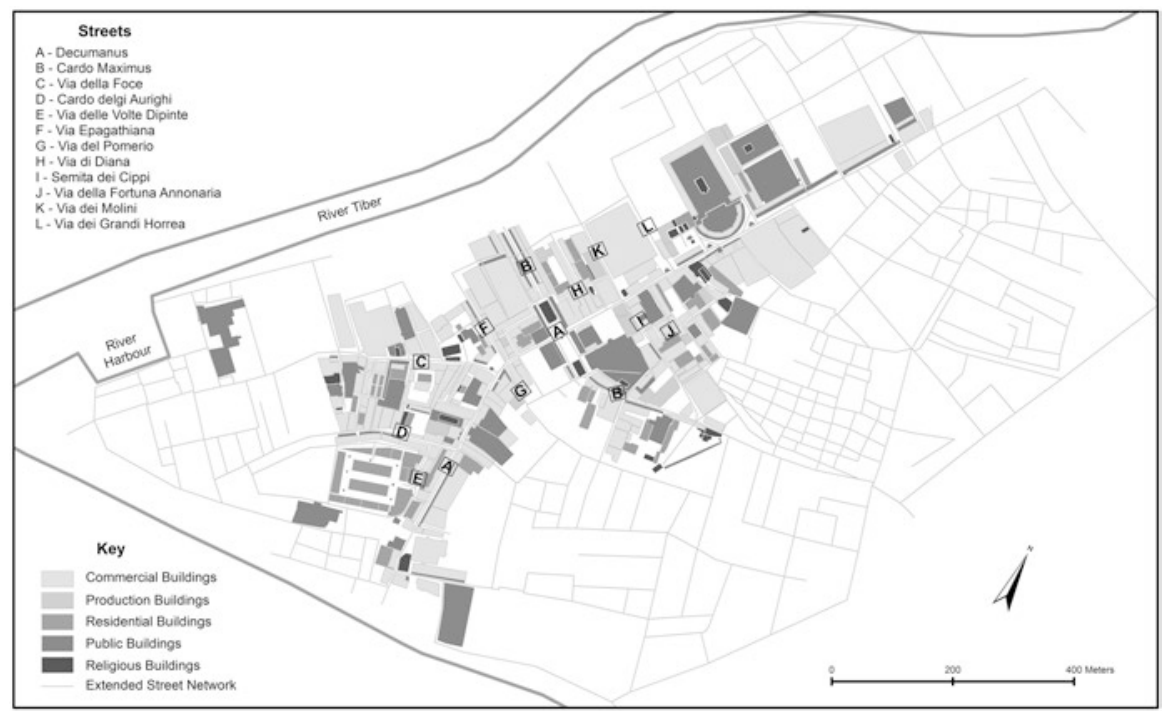

Fig. 15.1 Plan of Ostia at the end of the second century CE showing the building classifications and the main streets. (After Calza 1953; Mannucci 1995)

would not have had only one purpose. Instead, ground floor and upper storey spaces could have accounted for a variety of different activities, such as ground floor shops and storage rooms and upper storey residential spaces (Pirson 2007). For the present study, the classifications are indicative of ground floor spaces that are directly accessible from the street. Furthermore, the limitation of space classifications to five categories enables a workable dataset that begins to question how different aspects of the built environment structured movement patterns throughout Ostia.

The street network used within this study needs additional clarification. Within the excavated city, the streets date to the end of the second century CE (Mar 2008). In order to more accurately study movement patterns, the extended street network is additionally included following preliminary geophysical survey results (Heinzelmann 1998; Martin and Heinzelmann 2000) as well as the space syntax axial graph produced by Stöger (Stöger 2011) based upon these initial survey results. It needs to be noted that portions of the extended street network date to the beginning of the third century $\mathrm{CE}$, thereby slightly postdating the present period of study. However, until the geophysical survey results are fully published it is difficult to know exactly which sections of the street network date to which period. Therefore, the total extended street network is included in order to negate issues of an edge effect, or the creation of an artificial boundary, within the urban network analysis calculations by accounting for the possibility of movement travelling beyond the excavated city. While it needs to be acknowledged that any adjustment to the extended street network design may have some effect upon the network analysis results, the variation is less extreme than if only the excavated streets were used. 


\subsubsection{Urban Network Analysis}

Centrality measurements are one of the predominant network analysis calculations used by modern urban researches to investigate pedestrian movement. Until relatively recently, however, these measures have been used within the context of relational networks rather than accounting for geographical scale (Crucitti et al. 2006; Hillier and Hanson 1984). The concept of centrality is based upon the idea that within a network, certain nodes are more important. In terms of urban movement, centrality provides a way to determine likely areas of movement. Among the possible measurements, the most relevant for the present study is the application of betweenness centrality. Betweenness centrality computes the likelihood that a certain node, or in this case building, will be passed when travelling the shortest distance between two nodes (Brughmans 2010; Brughmans et al. 2016; Isaksen 2013). This enables the subsequent study of individual streets with a high degree of movement potential relative to the built environment. By focusing attention upon through movement, what is passed by pedestrians can be assessed regardless of their destination or origin. In this way, focus remains upon what is being passed regardless of the overall purpose of the journey.

Betweenness centrality graphs are traditionally computed using two network elements, nodes and edges. When applied to pedestrian studies on the scale of a city's street network, this correlates to nodes representing intersections while edges symbolize the streets (Porta et al. 2006). Space syntax, in contrast, inverts this network structure where the edges become nodes, and nodes represent edges (Hillier and Hanson 1984). In both of these types of network analyses, the level of enquiry is focused upon the spatial connection between the nodes and edges. However, within these network graphs, the relationship of the surrounding urban environment or related social activities remains unaccounted for within present movement-centred studies (Sevtsuk and Mekonnen 2012).

The vast majority of archaeological studies use betweenness centrality measures within the context of regional queries, focused upon the structure and connectivity of various sites (Bikoulis 2012; Brughmans 2010; Groenhuijzen and Verhagen 2015). Within these studies, the mobility of objects, people, or ideas within a landscape often becomes the emphasis of study. Despite the predominant applications of centrality to archaeological questions based upon regional scales, this does not limit its application to smaller urban datasets, such as a specific city (Mol and Mans 2013). The only existing example of betweenness centrality applied to an ancient urban street network is Poehler's (Poehler 2016) analysis of movement potential relative to doorways located along Pompeii's street system. While innovative in determining which Pompeiian streets saw the greatest amount of traffic by applying network analysis principals, it considers only generic movement patterns. Other urban factors that may have affected traffic within the city in addition to the network structure are unaccounted for within the present model.

To transition enquiry away from assessing movement in isolation to its surrounding built environment, urban network analysis is used to focus upon how buildings 
played a role in structuring movement along a street network using an adapted form of network analysis. Betweenness centrality is calculated in relation to the previously specified building classifications using the ArcGIS UNA (Urban Network Analysis) toolbox (Sevtsuk et al. 2016). The toolbox was created by urban planners as a way to question how the presence of buildings affects traditional centrality measurements (betweenness, centrality, reach, etc.) directly within GIS. Whereas standard network analysis is computed using nodes and edges, urban network analysis enables the addition of buildings as a third metric of study, creating a tripartite network. As a result, buildings become the focus of analysis, which are then computed in relation to their position along the street network previously detailed in ArcGIS. The betweenness centrality equation used by the UNA toolbox is adapted from Freeman (Freeman 1977) to highlight which buildings within the urban system saw the greatest potential of having passing movement along a street network. The results indicate the likelihood of a building being passed by through movement regardless of its destination or origin.

An innovative feature of the UNA toolbox and its application to archaeological questions of urban movement concerns the adaptability of the scale of measurement and the ability to attribute buildings with different variables or building weights. In terms of scale, a specific radius can be defined within the betweenness centrality calculations which limits the distance calculated from one building to all other buildings within the cityscape. Within modern cities a $400 \mathrm{~m}$ radius traditionally conforms to pedestrian scale movement while a $800 \mathrm{~m}$ radius is specific to vehicular traffic (Omer et al. 2015). However, these values do not necessarily directly relate to movement scale within the ancient city.

The best radius relative to pedestrian movement needs to be determined in relation to Ostia's built environment. A specified radius ensures that the centrality calculations of each building are computed only if a building is located within an equal or less geodesic distance from the specified radius from every other building along the street network (Sevtsuk and Mekonnen 2012). Additionally, calculations are computed using a network radius rather than a Euclidian radius to ensure that the results correspond to movement only occurring along the streets, not through buildings. To determine the ideal radius, six different betweenness centrality calculations were run using a 100-600 metre radius (Fig. 15.2). Within each betweenness graph, the buildings included within the highest betweenness centrality category (indicated in black) were then used as nodes to create a delineated area of greatest movement potential. Figure 15.2 shows that the greatest area of high movement potential is illustrated with a 100-300 metre radius; however, in these examples, movement is concentrated within either the western or eastern ends of the city. A 400 or 600 metre radius is more indicative of continuous movement across a larger portion of Ostia's cityscape. To ensure that the measurements correspond to both the excavated cityscape and local-scale pedestrian movement, a 400 metre radius is ultimately chosen.

A second feature of the UNA toolbox that has significant potential for the study of directed movement is the ability to weight buildings with different attributes. This can include variables such as a building's size, number of occupants, or 


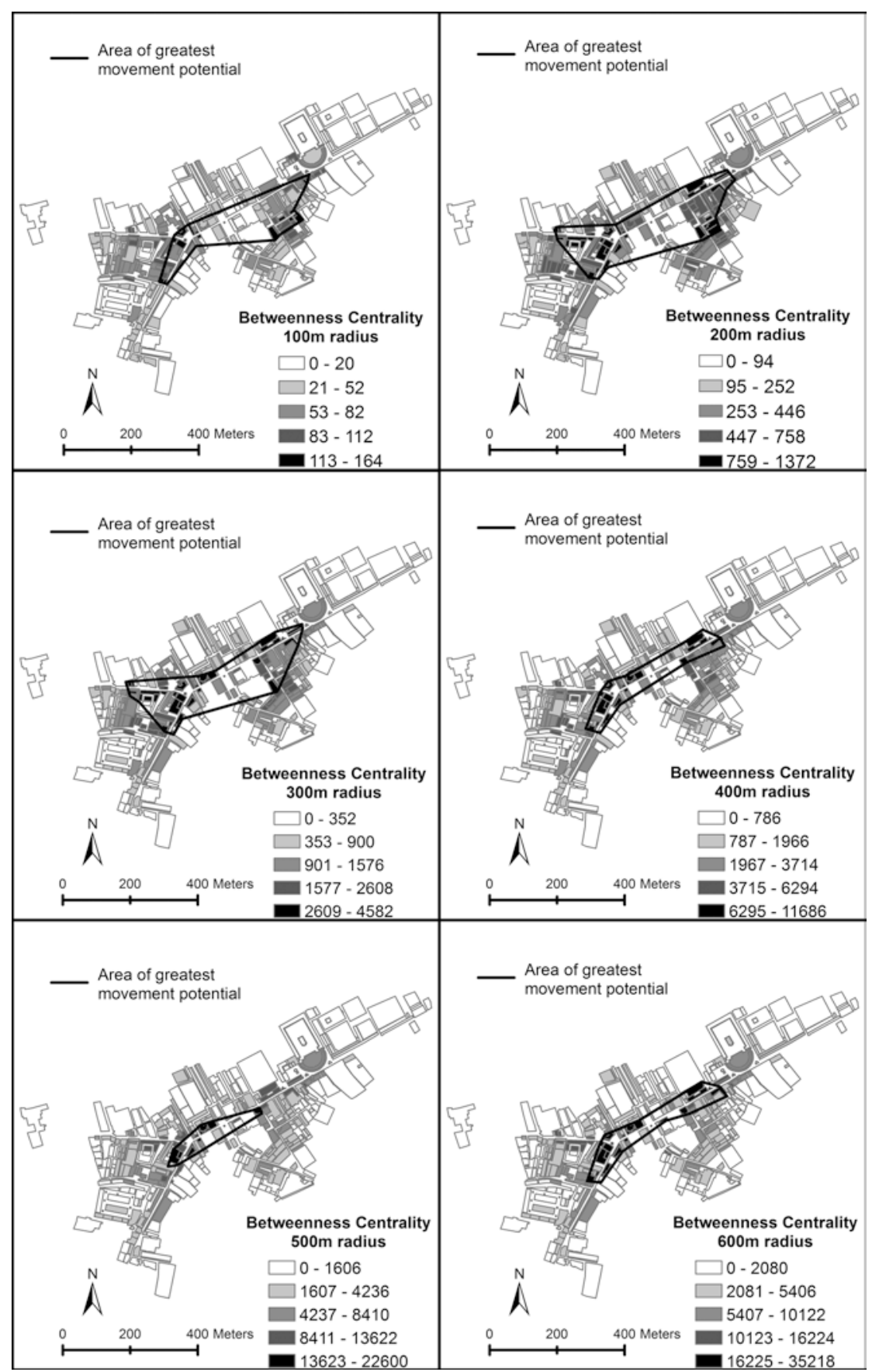

Fig. 15.2 Betweenness centrality measurements using a radius of 100-600 metres. The general areas with the highest betweenness values are detailed 
building type. For the present study, weighted values relate to the five different building classification categories and their individual influence upon passing movement. Betweenness centrality was run for each classification category, weighted with a value of 10 to reflect its assumed importance for pedestrian movement. The other four spaces were provided with a value of 1 to ensure that every building within the excavated cityscape is accounted for within the calculations (e.g., commercial spaces, weight 10; other four spaces, weight 1).

The application of betweenness centrality using Ostia's building classifications as the focus of analysis enables the assessment of what buildings were likely passed when weighted according to building type that is indicative of various social activities. The resulting betweenness centrality graphs (Figs. 15.3 and 15.4) present a visualization of the betweenness values relative to each building classification category. To more easily correlate this to possible movement routes, the streets corresponding to the two highest betweenness values are subsequently detailed. This enables a comparison between the different graphs to determine the extent to which the five building classifications affect pedestrian movement along Ostia's streets, ultimately reflecting distinct forms of movement intent.

\subsection{Results}

The calculation of betweenness centrality weighted by building importance gives some insight into the way in which social activity structured possible movement routes. To assess the degree to which weighted calculations affect the results, an unweighted betweenness centrality graph, applying a 400 m radius, was initially calculated (Fig. 15.3). The results illustrate the areas of the cityscape that saw the greatest potential of use. Ostia's primary street, the decumanus, has the highest degree of movement potential which correlates to the highest centrality measures. The areas of movement potential largely reflect how random movement is structured by the design of the built environment and the street network configuration if no other factors are taken into account. While the unweighted graph provides insight into the general configuration of the city for generating movement, weighted calculations begin to address the nuances of how the built environment structures movement depending upon what buildings are significant for passing pedestrian movement.

The calculation of weighted betweenness centrality shows some variation in results (Figs. 15.3 and 15.4), indicating that building importance can play a noticeable role in structuring movement directionality. While the highest betweenness centrality values stay relatively consistent throughout all of the graphs, variation is shown by the second highest betweenness value, represented by the top $40 \%$ intensity of street use visualization. This provides a clear indication that building importance has a direct correlation to potential movement routes. 


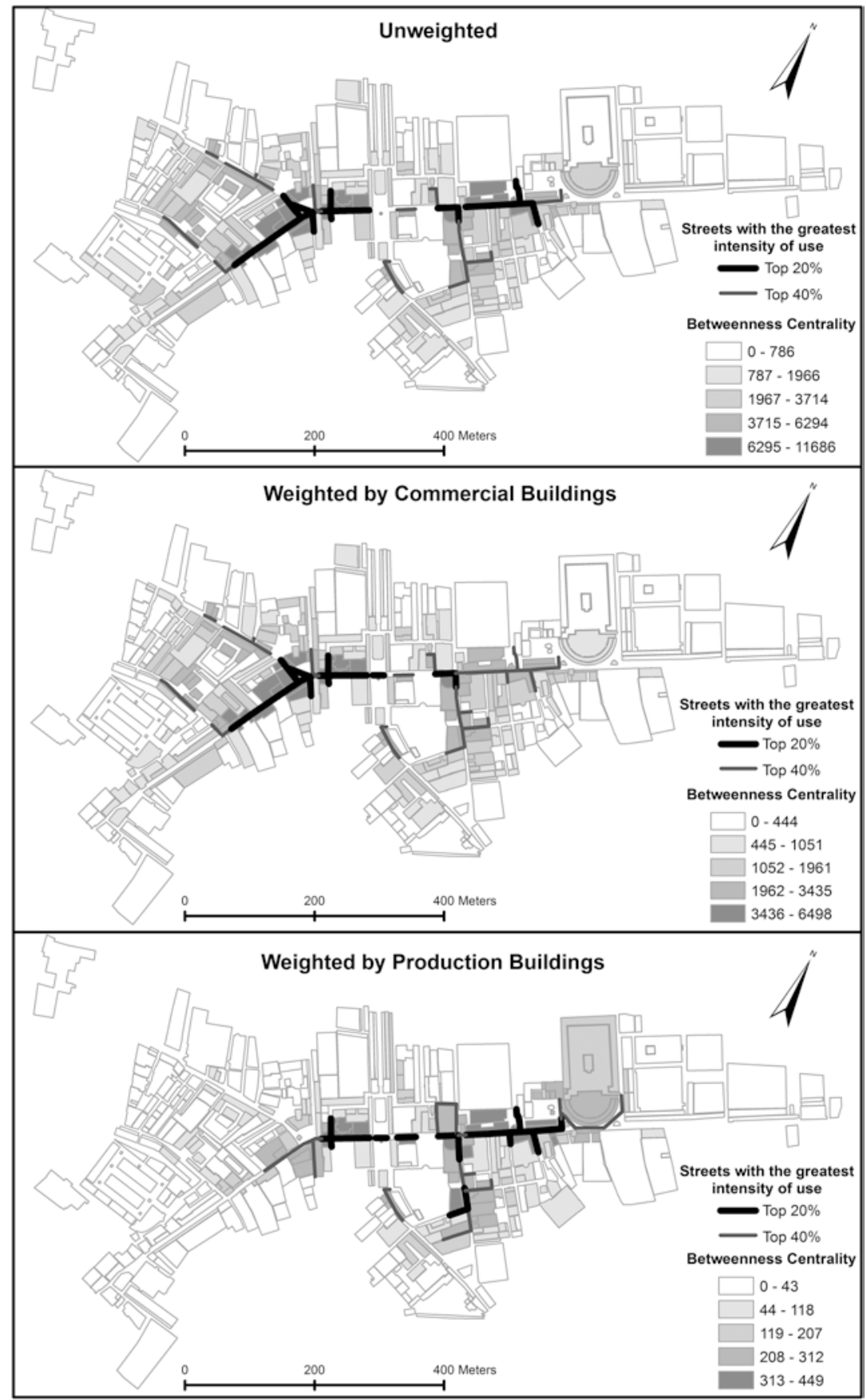

Fig. 15.3 Betweenness centrality measurements following unweighted buildings, commercial weighted buildings, and production weighted buildings and the corresponding streets with the greatest intensity of use (radius, $400 \mathrm{~m}$ ) 


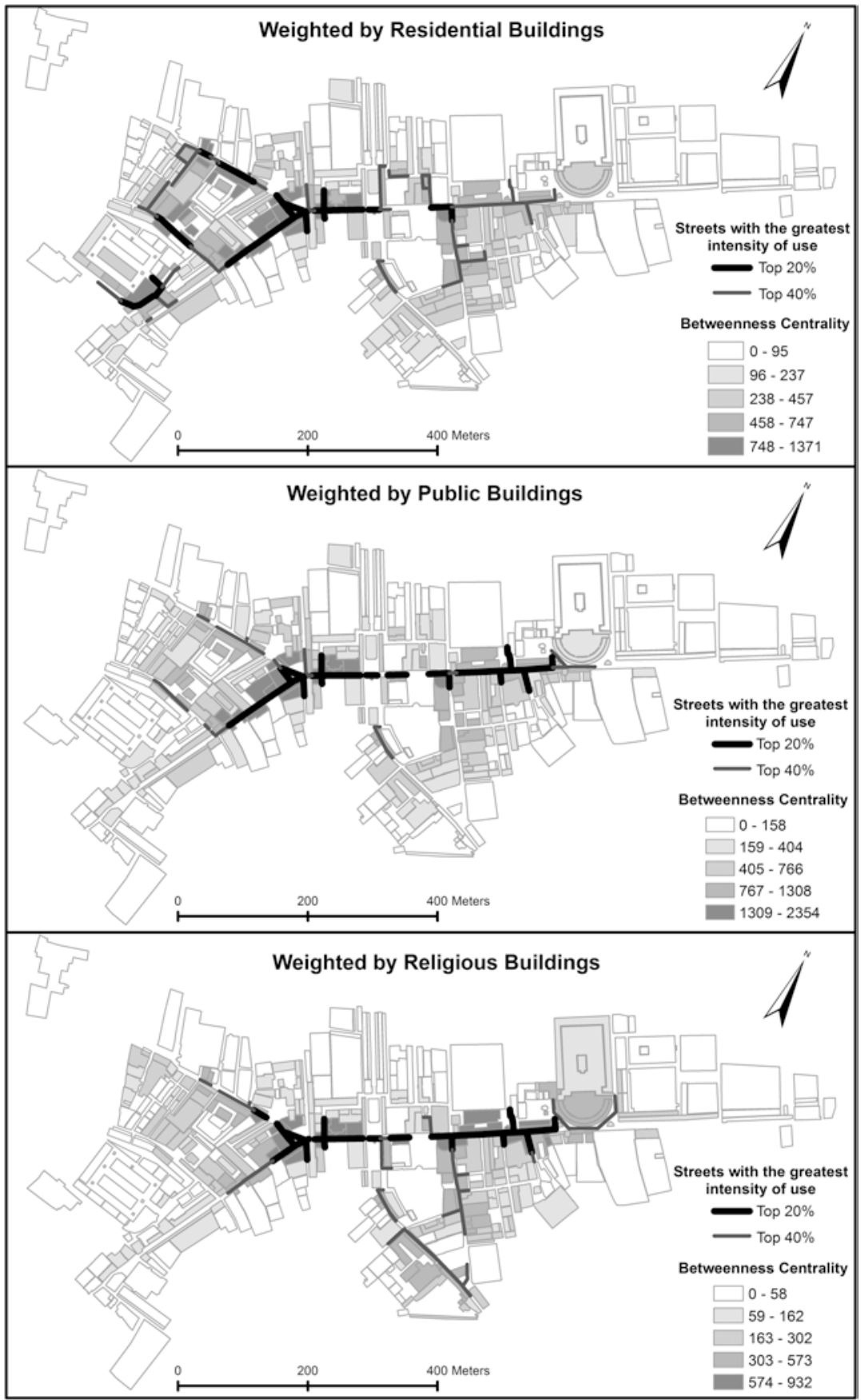

Fig. 15.4 Betweenness centrality measurements following residential weighted buildings, public weighted buildings, and religious weighted buildings and the corresponding streets with the greatest intensity of use (radius, $400 \mathrm{~m}$ ) 


\subsection{Discussion}

A range of different movement patterns become visible through the calculation of betweenness centrality when applying urban network analysis (Figs. 15.3 and 15.4). The results, when compared to the unweighted calculation of betweenness centrality shown in Fig. 15.3, indicate that building functionality has a notable effect upon areas of movement. While the movement potential along streets can be attributed in part to how various buildings have been classified, the potential of the method for exploring questions of how building type affected areas of urban movement is evident.

Movement along the city's primary street, the decumanus, has the greatest movement potential within all of the weighted betweenness calculations. The western portion of the decumanus sees predominant use within the commercial and residential weighted calculations. The production and religious weighted graphs show the greatest intensity of movement occurring along the eastern portion of the decumanus. When weighted by public buildings, in contrast, the results indicate a relatively even dispersal, which likely corresponds to the number of public buildings that are accessible from this street.

The Via della Foce, one of Ostia's secondary streets, sees a substantial amount of likely passage. Residential and religious weighted graphs have the greatest percentage of potential movement along this street, while commercial and public have the second highest probability of use. This street's high degree of movement activity is not surprising considering its connection to the decumanus and that it leads to the city's river harbour that is located northwest of the excavated city.

A less consistently used street is the Cardo degli Aurighi, which parallels the Via della Foce. The residential weighted graph shows that this street has a high degree of use, which is unsurprising considering the concentration of residential spaces located within its vicinity. The other betweenness graphs indicate that it has some degree of movement potential when the calculations are weighted by both commercial and public buildings. In these two examples, the street has the second highest degree of movement potential. Movement along the internal streets connecting both the Cardo degli Aurighi and the Via della Foce also occurs only when weighted by residential space. This provides an indication that potential movement routes can have noticeable variation depending upon what structures are deemed important for movement travelling throughout the city.

The Semita dei Cippi, which extends south off of the eastern decumanus has an inconsistent degree of use. All of the betweenness graphs, except for the public weighted measurements, indicate that this street has the second highest probability of use. In terms of Ostia's commercial movement economy, this street likely saw an increased amount of commercial traffic since the street served as a connection between Ostia's southern entrance gate and the Tiber (DeLaine 2005; Mar 2008).

The final street that sees a medium degree of use is the cardo maximus. The southern cardo maximus consistently has the second highest probability of use. When weighted by religious structures, this area of movement extends to the limits 
of the excavated portion of the street. The northern cardo maximus sees a bit more variation in usage. Production and residential weighted graphs show the greatest probability of movement travelling towards the northern cardo maximus. This correlates to the concentration of apartment buildings located within the vicinity of this street as well as a number of production buildings positioned near the Tiber. The other weighted classifications show little potential of movement travelling along Ostia's northern streets. Considering the number of warehouses and storage buildings located along the Tiber's edge, it is unsurprising that movement within parts of the northern city is limited.

The results of these different weighted betweenness centrality graphs all show the degree to which buildings influenced possible areas of movement throughout the second century CE cityscape. When compared to the unweighted betweenness centrality graph (Fig. 15.3), the five weighted calculations (Figs. 15.3 and 15.4) provide a visual representation about how movement directionality can change when study is focused upon what is being passed rather than just the structure of a city's street network.

\subsection{Conclusion}

This paper has aimed to introduce a new approach for studying directed pedestrian movement by applying urban network analysis to assess how building usage shapes potential movement areas. By moving enquiry beyond traditional approaches that focus upon how the construct of the street network promotes pedestrian movement, the calculation of betweenness centrality using building importance at a weighted scale shows distinct areas of movement potential. The results indicate that there is noticeable variation in possible routes at Ostia depending upon what types of buildings are most influential to pass.

The framework introduced above for studying movement intent can be subsequently tied to more detailed questions concerning Ostia's built environment. This could range from considering how additional building classifications or the occupancy size of buildings effects movement throughout the city. The results provide a heuristic tool for assessing how different aspects of Ostia's built environment impact movement throughout the city, allowing different assumptions to be tested. At present, only one building was weighted, but future analyses can assess how different combined weights of building types affect the betweenness results. This paper has illustrated the possibility of studying how pedestrian movement may have been shaped by different urban factors at Ostia. The application of urban network analysis shows significant potential for enabling new avenues of research to be developed that consider the nuances of urban pedestrian movement. 


\section{References}

Barthelemy M (2011) Spatial networks. Phys Rep 499:1-101. https://doi.org/10.1016/j. physrep.2010.11.002

Bikoulis P (2012) Revisiting prehistoric sites in the Göksu valley: a GIS and social network approach. Anatol Stud 62:35-59. https://doi.org/10.1017/S0066154612000026

Branting S (2004) Iron age pedestrians at Kerkenes Dağ: an archaeological GIS-T approach to movement and transportation. State University of New York, Buffalo

Brughmans T (2010) Connecting the dots: towards archaeological network analysis. Oxf J Archaeol 29(3):277-303. https://doi.org/10.1111/j.1468-0092.2010.00349.x

Brughmans T, Collar A, Coward F (eds) (2016) The connected past. Challenges to network studies in archaeology and history. Oxford University Press, Oxford

Calza G (ed) (1953) Scavi di Ostia I. Topografia generale. Poligrafico dello Stato, Rome

Crucitti P, Latora V, Porta S (2006) Centrality measures in spatial networks of urban streets. Phys Rev E 73(36125):1-5. https://doi.org/10.1103/PhysRevE.73.036125

DeLaine J (2002) Building activity in Ostia in the second century AD. In: Bruun C, Gallina Zevi A (eds) Ostia e Portus nelle loro relazioni con Roma. Acta Instituti Romani Finlandiae 27:41-101

DeLaine J (2005) The commercial landscape of Ostia. In: MacMahon A, Price J (eds) Roman working lives and urban living. Oxbow, Oxford, pp 29-47

Ellis S (2004) The distribution of bars at Pompeii: archaeological, spatial and viewshed analyses. J Roman Archaeol 17:371-384. https://doi.org/10.1017/S104775940000831X

Favro D (1996) The urban image of Augustan Rome. Cambridge University Press, Cambridge

Flohr M (2013) The world of the fullo: work, economy, and society in Roman Italy. Oxford University Press, Oxford. https://doi.org/10.1093/acprof:oso/9780199659357.001.0001

Freeman L (1977) A set of measures of centrality based on betweenness. Sociometry 40(1):35-41. https://doi.org/10.2307/3033543

Groenhuijzen MR, Verhagen P (2015) Exploring the dynamics of transport in the Dutch limes. eTopoi J Anc Stud Spec Issue 4:25-47. Available at http://journal.topoi.org/index.php/etopoi/ article/view/203/227. Accessed on 10 May 2018

Hartnett J (2008) Si quis hic sederit: streetside benches and urban society in Pompeii. Am J Archaeol 112(1):91-119. https://doi.org/10.3764/aja.112.1.91

Hartnett J (2017) The Roman street: urban life and society in Pompeii, Herculaneum, and Rome. Cambridge University Press, New York. https://doi.org/10.1017/9781316226438

Heinzelmann M (1998) Beobachtungen zur suburbanen topographie Ostias. Ein orthogonales strassensystem im bereich der Pianabella. Mitteilungen des Deutschen Archäologischen Instituts. Römische Abteilung 105:175-225

Heinzelmann M (2005) Die vermietete Stadt. In: Neudecker R, Zanker P (eds) Lebenswelten. Bilder und Räume in der römischen Stadt der Kaiserzeit. Reichert, Wiesbaden, pp 113-128

Hillier B, Hanson J (1984) The social logic of space. Cambridge University Press, Cambridge. https://doi.org/10.1017/CBO9780511597237

Isaksen L (2013) 'O what a tangled web we weave' - towards a practice that does not deceive. In: Knappett C (ed) Network analysis in archaeology: new approaches to regional interaction. Oxford University Press, Oxford, pp 43-67. https://doi.org/10.1093/acprof: oso/9780199697090.003.0003

Jacobs J (1961) The death and life of great American cities. Random House, New York

Kaiser A (2011) Roman urban street networks. Routledge, New York

Kostof S (1985) A history of architecture: settings and rituals. Oxford University Press, New York

Laurence R (2008) City traffic and the archaeology of Roman streets from Pompeii to Rome. In: Mertens D (ed) Stadtverkehr in der antiken welt. Reichert, Wiesbaden, pp 87-106

Laurence R (2011) Literature and the spatial turn: movement and space in Martial's Epigrams. In: Laurence R, Newsome D (eds) Rome, Ostia, Pompeii: movement and space. Oxford University Press, Oxford, pp 81-99. https://doi.org/10.1093/acprof:osobl/9780199583126.003.0003 
Laurence R, Newsome D (eds) (2011) Rome, Ostia, Pompeii: movement and space. Oxford University Press, Oxford. https://doi.org/10.1093/acprof:osobl/9780199583126.001.0001

Lawrence D, Low S (1990) The built environment and spatial form. Annu Rev Anthropol 19:453505. https://doi.org/10.1146/annurev.an.19.100190.002321

Lynch K (1960) The image of the city. MIT Press, Cambridge (MA)

Macaulay-Lewis E (2011) The city in motion: walking for transport and leisure in the city of Rome. In: Laurence R, Newsome D (eds) Rome, Ostia, Pompeii: movement and space. Oxford University Press, Oxford, pp 262-289. https://doi.org/10.1093/acprof:os obl/9780199583126.003.0012

MacDonald WL (1986) The architecture of the Roman Empire II: an urban appraisal. Yale University Press, New Haven (CT)/London

Mannucci V (1995) Atlante di Ostia antica. Marsilio, Venice

Mar R (2008) Il traffico viario a Ostia: spazio pubblico e progetto urbano. In: Mertens D (ed) Stadtverkehr in der antiken Welt. Reichert, Wiesbaden, pp 125-144

Martin A, Heinzelmann M (2000) The joint AAR-DAI research project at Ostia: 1998 and 1999 seasons. Mem Am Acad Rome 45:277-283. https://doi.org/10.2307/4238773

Meiggs R (1973) Roman Ostia, 2nd edn. Oxford University Press, Oxford

Mol A, Mans J (2013) Old-boy networks in the indigenous Caribbean. In: Knappett C (ed) Network analysis in archaeology: new approaches to regional interaction. Oxford University Press, Oxford, pp 307-327. https://doi.org/10.1093/acprof:oso/9780199697090.003.0013

Omer I, Rofè Y, Lerman Y (2015) The impact of planning on pedestrian movement: contrasting pedestrian movement models in pre-modern and modern neighborhoods in Israel. Int J Geogr Inf Sci 29(12):2121-2142. https://doi.org/10.1080/13658816.2015.1063638

Östenberg I, Malmberg S, Bjørnebye J (eds) (2015) The moving city: processions, passages and promenades in ancient Rome. Bloomsbury Academic, London

Packer JE (1971) The insulae of imperial Ostia. Mem Am Acad Rome 31:1-217. https://doi. org/10.2307/4238664

Pavolini C (2006) Ostia. GLF Editori Laterza, Rome

Pavolini C (2016) A survey of excavations and studies on Ostia (2004-2014). J Roman Stud 106:199-236. https://doi.org/10.1017/S0075435816001015

Pirson F (2007) Shops and industries. In: Dobbins JJ, Foss PW (eds) The world of Pompeii. Routledge, New York, pp 457-473

Poehler E (2016) Measuring the movement economy: a network analysis of Pompeii. In: Flohr M, Wilson A (eds) The economy of Pompeii. Oxford University Press, Oxford, pp 163-208. https://doi.org/10.1093/acprof:oso/9780198786573.003.0007

Poehler E (2017) The traffic systems of Pompeii. Oxford University Press, Oxford

Porta S, Crucitti P, Latora V (2006) The network analysis of urban streets: a primal approach. Environ Plann B 33:705-725. https://doi.org/10.1068/b32045

Rapoport A (1982) The meaning of the built environment: a nonverbal communication approach. Sage Publications, Beverly Hills (CA)

Russell A (2016) The politics of public space in republican Rome. Cambridge University Press, Cambridge. https://doi.org/10.1017/CBO9781139629041

Sarkar S (2013) Street network analysis for understanding typology in cities. Case study on Sydney CBD and suburbs. In: Ruming K, Randolph B, Gurran N (eds) State of Australian cities conference 2013: refereed proceedings. State of Australian Cities Research Network, Sydney, pp 1-9

Sevtsuk A, Mekonnen M (2012) Urban network analysis toolbox. Int J Geomatics Spat Anal 22(2):287-305. https://doi.org/10.3166/rig.22.287-305

Sevtsuk A, Mekkonen M, Kalvo R (2016) Urban network analysis: toolbox for ArcGIS 10/10.1/10.2. City Form Lab, Harvard University, Cambridge (MA), Available at http://media. voog.com/0000/0036/2451/files/20160120_UNA_help_v1_1.pdf. Accessed on 12 May 2018

Stöger H (2011) Rethinking Ostia: a spatial enquiry into the urban society of Rome's imperial port-town. Leiden University Press, Leiden 
Thaler U (2005) Narrative and syntax: new perspectives on the Late Bronze Age palace of Pylos, Greece. In: Van Nes A (ed) Proceedings of the 5th international space syntax symposium. Techne Press, Amsterdam, pp 324-339

Van Nes A (2014) Indicating street vitality in excavated towns. Spatial configurative analyses applied to Pompeii. In: Paliou E, Lieberwirth U, Polla S (eds) Spatial analysis and social spaces: interdisciplinary approaches to the interpretation of prehistoric and historic built environments. De Gruyter, Berlin, pp 277-296. https://doi.org/10.1515/9783110266436.277

Yegül FK (1994) The street experience of ancient Ephesus. In: Çelik Z, Favro D, Ingersoll R (eds) Streets: critical perspectives on public space. University of California Press, Berkeley, pp 95-110

Open Access This chapter is licensed under the terms of the Creative Commons Attribution 4.0 International License (http://creativecommons.org/licenses/by/4.0/), which permits use, sharing, adaptation, distribution and reproduction in any medium or format, as long as you give appropriate credit to the original author(s) and the source, provide a link to the Creative Commons licence and indicate if changes were made.

The images or other third party material in this chapter are included in the chapter's Creative Commons licence, unless indicated otherwise in a credit line to the material. If material is not included in the chapter's Creative Commons licence and your intended use is not permitted by statutory regulation or exceeds the permitted use, you will need to obtain permission directly from the copyright holder. 